\title{
Cardiac performance in hypertension re-evaluated through a combined haemodynamic ultrasonic method
}

\author{
CESARE FIORENTINI, ALVISE POLESE, MARIA T OLIVARI, \\ MAURIZIO D GUAZZI

\begin{abstract}
From Istituto Ricerche Cardiovascolari 'Giorgio Sisini', Centro Ricerche Cardiovascolari del Consiglio Nazionale delle Ricerche, Clinica Medica II, Cattedra di Cardiologia, University of Milan, Milan, Italy
\end{abstract}

SUMMARY From echocardiographic measurements, 39 patients with established, uncomplicated primary hypertension (diastolic pressure $>100 \mathrm{mmHg}$ ) were classified as follows: normal-sized heart (group 1, 10 cases); concentric left ventricular hypertrophy (group 2, 18 cases); left ventricular hypertrophy and cavity enlargement (group 3,11 cases). Eighteen age-matched healthy subjects were investigated as a control group.

Systolic and diastolic arterial pressure increased progressively from group 1 to 2 to 3 . Left ventricular function, assessed from the relation between diastolic diameter and stroke index, was maintained in group 1, increased in group 2 (in spite of the greater pressure load), and reduced in group 3, in comparison with controls. Similarly, the mean velocity of circumferential fibre shortening (VCF) was normal in group 1 , significantly increased in group 2 , and reduced in group 3 . It was impossible to discern whether the different behaviour of VCF in group 2 and in group 3 reflected opposite changes in ventricular contractility, or in wall stress during ejection, or in both.

At variance with previous conclusions (which were based on utilisation of electrocardiographic and chest $x$-ray criteria to define hypertrophy) it is suggested that left ventricular concentric hypertrophy in man consequent to sustained hypertension is associated with an improved function. Whether this feature depends upon an augmented contractility or a ventricular unloading effect related to hypertrophy remains uncertain.

Afterload is a major determinant of left ventricular function in systemic hypertension. At comparable levels of arterial pressure and vascular resistance, afterload may be reduced when ventricular hypertrophy develops, or increased when the cavity becomes enlarged. Evaluation of cardiac performance in hypertension requires a precise assessment of the circulatory load as well as the ventricular dimensions and wall thickness.

In earlier clinical studies, including our own, ${ }^{1-3}$ it was reported that the performance of the hypertrophied heart was impaired in hypertensive patients. There are, however, reasons for reconsidering the validity of this conclusion: thus, conventional electrocardiographic criteria for hypertrophy have obvious limitations arising from the occurrence of false-positive ${ }^{4}$ and false-negative ${ }^{5}$ diagnoses; in addition, chest $x$-ray criteria of left ventricular enlargement to diagnose hypertrophy ${ }^{2}$ evidently precludes a separate analysis of concentric hyper-

Received for publication 5 March 1979 trophy and, respectively, dilatation of the left ventricle.

Echocardiography provides an accurate method for the estimation of left ventricular wall thickness and dimensions; the ultrasound method identifies concentric hypertrophy more often than electrocardiograms or chest $x$-rays ${ }^{6}$; echocardiography also makes it possible to integrate haemodynamic findings and measurements of wall stress. ${ }^{7}$ A combination of the two methods was used in a large hypertensive population in this study.

\section{Subjects and methods}

Thirty-nine men in hospital with primary systemic arterial hypertension were the subjects of this investigation. All had repeated sphygmomanometric blood pressure readings of $180 / 100 \mathrm{mmHg}$ or more. Patients were selected who were less than 60 years of age, and had no history or signs of heart failure, pulmonary disease, valve lesions, coronary heart disease, or idiopathic myocardial disease. All had normal serum electrolyte concentrations; all were 
in regular sinus rhythm without conduction abnormalities; none had received digitalis at any time or antihypertensive treatment for at least one month. In all it was possible to record a technically satisfactory left ventricular echocardiogram; subjects were excluded who had a ratio of septal to posterior wall thickness greater than 1.3 , or abnormal interventricular septal motion. Patients were not included if they were in urgent need of treatment.

A control group of 18 subjects included healthy volunteers and patients who had no signs of cardiovascular disease and who were taking no drugs with any action on the cardiovascular system. All subjects gave free consent to the investigation in the full knowledge of the procedures to be undertaken. Hypertensives were divided into three groups according to the following echocardiographic criteria: group 1 (10 cases) consisted of subjects in whom septal and posterior wall thickness and enddiastolic left ventricular minor axis were within one standard deviation of the normal control measurement; group 2 (18 cases) consisted of subjects with normal or reduced left ventricular minor axis and both septal and posterior wall thickness exceeding mean plus one standard deviation of control measurement; in group 3 (11 cases), wall thickness was within the same range as in group 2 but enddiastolic minor axis exceeded the mean plus one standard deviation for this group. These criteria defined the structural characteristics of the heart: normal heart (group 1), concentric hypertrophy (group 2), hypertrophy associated with left ventricular cavity enlargement (group 3). Examples of echocardiograms in each hypertensive group are illustrated in Fig. 1.

\section{HAEMODYNAMIC METHODS}

One week after admission, after the diagnosis of essential hypertension had been established, and after the patients had been familiarised with the laboratory and with the investigators, circulatory measurements were performed in the fasting state, in the supine position, without premedication. A no. 7 flow-directed Swan-Ganz catheter was inserted into an antecubital vein and advanced to the pulmonary artery and to the wedge position. A no. 6 radiopaque polyethylene catheter, introduced percutaneously into a brachial artery, was advanced to the root of the aorta, and was used to monitor arterial pressure and to withdraw blood for dye dilution cardiac output measurements. Reproducible dye dilution curves were obtained using a Gilford densitometer after rapid injection of indocyanine green dye $(5 \mathrm{mg})$ into the main pulmonary artery. The area under each dye dilution curve was measured by planimetry and cardiac output calculated by the standard Hamilton method. Pressures were measured using Statham P23de and P23db strain gauge transducers (zero reference level $5 \mathrm{~cm}$ below sternal angle). Mean pressures
Group 1

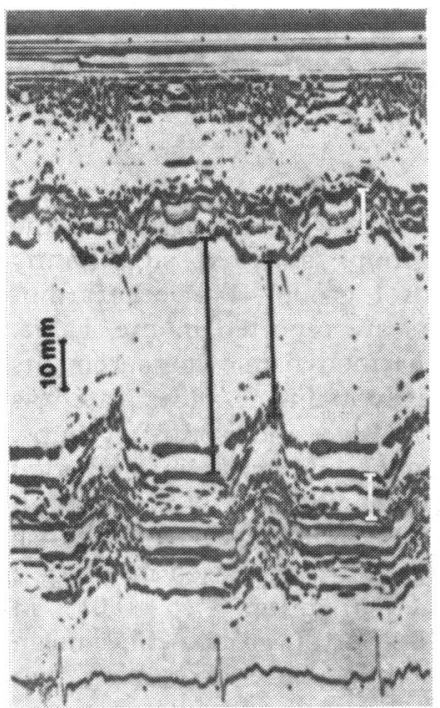

Group 2

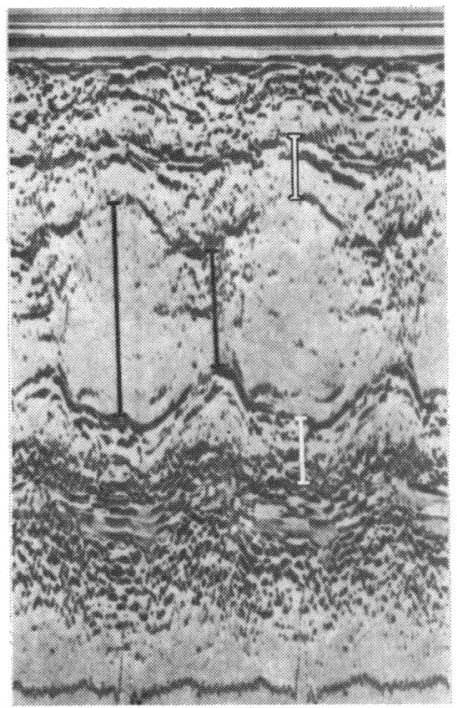

Group 3

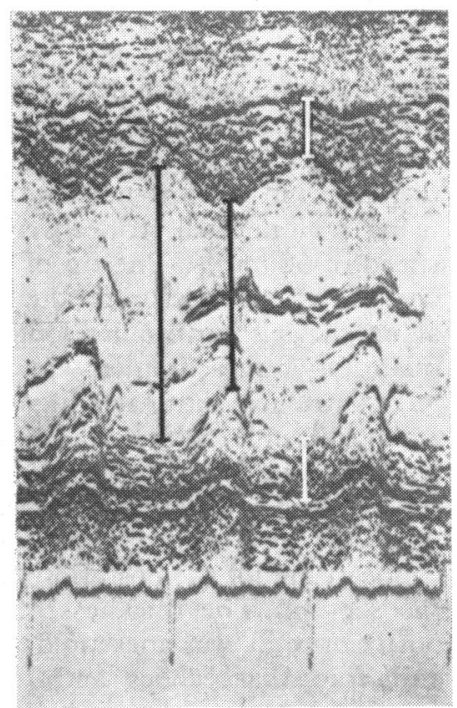

Fig. 1 Examples of left ventricular echocardiogram in the three hypertensive groups. Wall thickness and systolic and diastolic diameters are indicated by white and black lines, respectively. 
were obtained by electronic damping. Left ventricular ejection time was measured from the aortic pressure pulse recorded at a paper speed of $100 \mathrm{~mm} / \mathrm{s}$; measurements were made to the nearest $5 \mathrm{~ms}$ from the beginning of the upstroke to the trough of the incisura on five consecutive beats and an average value calculated. Mean systolic ejection rate (MSER) was determined by dividing the stroke index by the left ventricular ejection time. Systemic vascular resistance $(-5)$ was calculated using the formula:

$$
\operatorname{SVR}\left(\text { dynes } \mathrm{s} \mathrm{cm}^{-5}\right)=\frac{\overline{\mathrm{AP}}-\overline{\mathrm{RAP}} \times 1.332 \times 60}{\mathrm{CO}}
$$

where $\overline{\mathrm{AP}}$ is arterial mean pressure $(\mathrm{mmHg}), \overline{\mathrm{RAP}}$ is right atrial mean pressure $(\mathrm{mmHg})$, and $\mathrm{CO}$ is cardiac output $(1 / \mathrm{min})$.

\section{ECHOCARDIOGRAPHIC METHODS}

An Echo-Cardio-Visor ultrasound unit (Organon Teknika) was used. Ultrasound measurements of the left ventricle were made as described by Feigenbaum et al. ${ }^{8}$ Patients were lying, turned slightly to the left, with $20^{\circ}$ elevation of the head; the transducer was placed in the third or fourth intercostal space to the left of the sternum and was directed posteriorly and medially until the characteristic pattern of mitral valve motion was observed. The ultrasonic beam was then directed laterally and slightly inferiorly to locate a plane in which the interventricular septum and the endocardium and epicardium of the left ventricular posterior wall could be observed simultaneously. The gain, damping, and reject controls were adjusted to display echoes from these structures optimally, to show their characteristic patterns of motion. These were displayed in a time-motion mode and recorded using a Honeywell strip chart recorder at a paper speed of $50 \mathrm{~mm} / \mathrm{s}$. The tip of the mitral valve was chosen as the best reproducible reference point along the left ventricular long axis for comparing quantitative measurements in different hearts. The left ventricular internal dimensions were measured at end-diastole at the time of the $R$ wave of the electrocardiogram, and at end-systole at a time when the distance between the posterior wall and septum was least; the measurements were made from the endocardium of the posterior wall to the left side of the septum. The thickness of the left ventricular posterior wall was measured between endocardial and epicardial echoes and the thickness of the septum between the right and left ventricular endocardial echoes at end-diastole. From these measurements left ventricular circumferential wall stress (CWS) and mean velocity of circumferential shortening (VCF) were calculated. Circumferential wall stress (dynes $/ \mathrm{cm}^{2}$ ) at the time of aortic valve opening was taken as an index of left ventricular preejection afterload, and was calculated using the formula of Sandler and Dodge, ${ }^{9}$ modified by Ratshin et al. ${ }^{10}$ :

$$
\mathrm{CWS}=\frac{\mathrm{PD} / 2}{\mathrm{~h}}\left(1-\frac{\mathrm{D}}{8(\mathrm{D}+\mathrm{h})}\right) \times 1334
$$

where $P$ is the aortic diastolic pressure $(\mathrm{mmHg})$, $\mathrm{D}$ is the left ventricular internal minor dimension $(\mathrm{cm})$, and $\mathrm{h}$ is the left ventricular posterior wall thickness $(\mathrm{cm})$. The normalised mean velocity of circumferential fibre shortening (circ/s) was calculated using the equation of Fortuin et al. ${ }^{11}$ :

$$
\mathrm{VCF}=\frac{\mathrm{D}_{\mathrm{D}}-\mathrm{S}_{\mathrm{D}}}{\mathrm{LVET} \times \mathrm{D}_{\mathrm{D}}}
$$

where $\mathrm{DD}$ is the end-diastolic diameter $(\mathrm{cm})$, SD is the end-systolic diameter $(\mathrm{cm})$, and LVET is the left ventricular ejection time (s). All the haemodynamic and echocardiographic measurements were made in the steady state, when patients were comfortable and heart rate and pressures stable; in all cases measurements were begun at least 30 minutes after completing the catheterisation procedure. Measurements were made twice, at 15-minute intervals, and the average of the two measurements calculated. Statistical significance of the differences between the groups was evaluated by analysis of variance.

\section{Results}

Age and body surface area were comparable in the three hypertensive groups and not significantly different in the control group. The echocardiographic measurements are reported in the Table. The averages of the haemodynamic measurements are presented graphically in Fig. 2. Heart rate was similar in the hypertensive and control groups. Arterial pressure (systolic and diastolic) and total peripheral resistance were significantly increased in all three hypertensive groups $(p<0.01)$. Cardiac index was normal in group 1 , increased in group 2 $(p<0.05)$, and reduced in group $3(p<0.01)$, in comparison with the control group. The mean velocity of circumferential fibre shortening was normal in group 1, but was increased in group 2 $(p<0.01)$, and reduced in group $3(p<0.01)$. The changes in mean systolic ejection rate were similar; 
the differences were related to larger stroke index and shorter ejection time in group 2 and to smaller stroke index and longer ejection time in group 3, in comparison with the control group. Pre-ejection left ventricular circumferential wall stress was increased in groups 1 and $3(p<0.01)$, and slightly reduced in group 2 compared with the control group. Because of the nature of the formula for wall stress, the raised aortic diastolic pressure in group 1 accounted for the increased circumferential wall stress in this group. In group 2, in spite of the raised aortic diastolic pressure, circumferential wall stress was unchanged or even reduced; this was related to the increased wall thickness associated
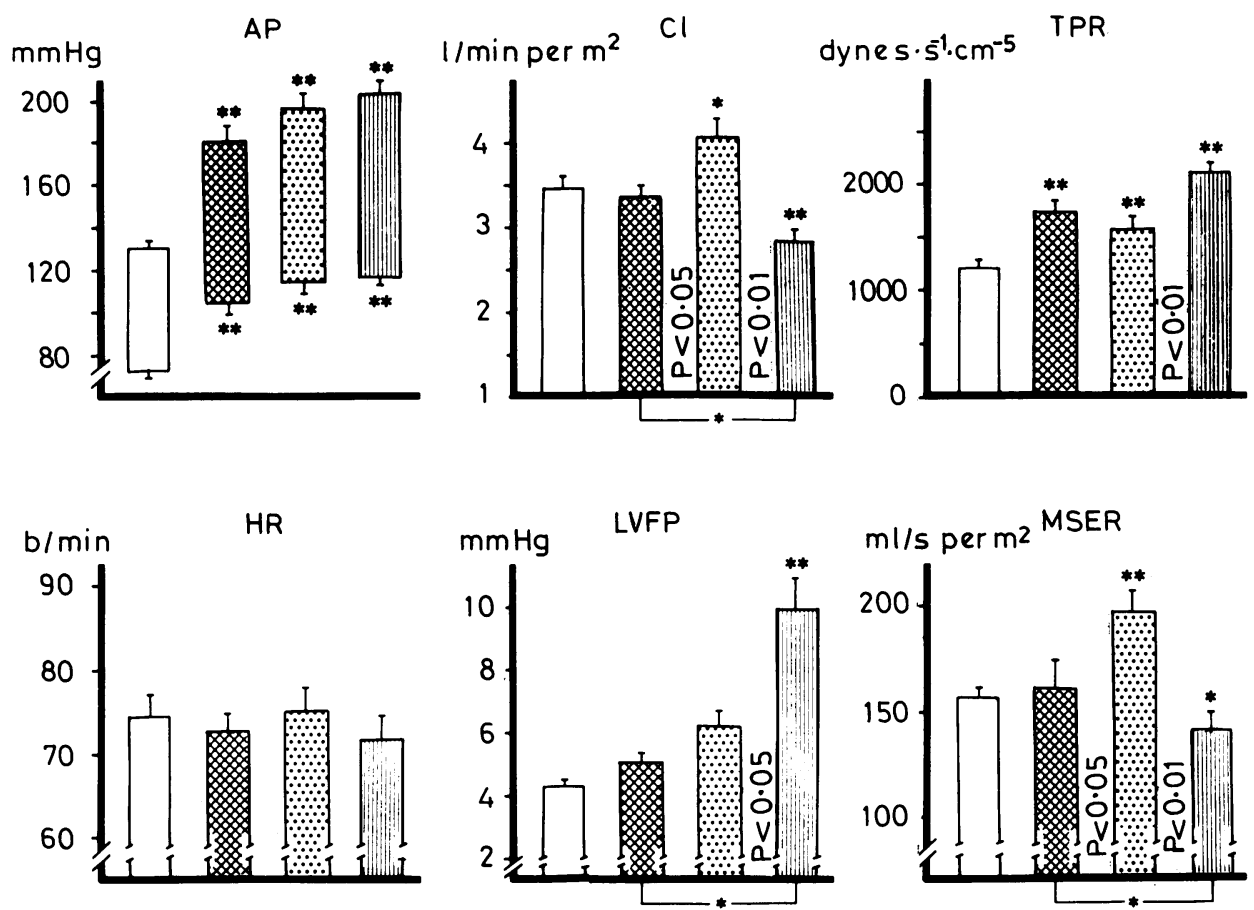
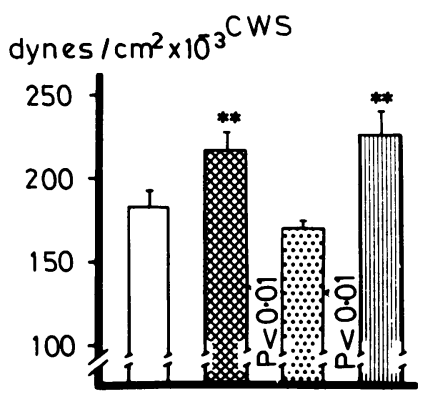

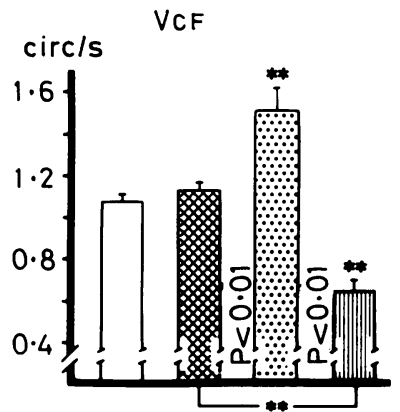

Fig. 2 Haemodynamic measurements in 18 normal control subjects and in three groups of patients with essential hypertension. Group 1, 10 patients with normal-sized heart; group 2, 18 patients with concentric left ventricular hypertrophy; group 3, 11 patients with hypertrophy and left ventricular cavity enlargement. Bars represent the mean and SEM for the group. ${ }^{*}$ and $\star \star$ indicate $p$ values of $<0.05$ and $<0.01$, respectively, for differences between hypertensive groups and controls; $p$ values for differences between the hypertensive groups are also shown in the figure. $A P$, arterial pressure (systolic and diastolic); $C I$, cardiac index; $T P R$, total peripheral vascular resistance; $H R$, heart rate, LVFP, left ventricular filling pressure; $M S E R$, mean rate of systolic ejection; $C W S$, circumferential wall stress; $V_{C F}$, mean rate of circumferential fibre shortening. 
Table Echocardiographic values (averages and SD)

\begin{tabular}{|c|c|c|c|c|}
\hline Groups & $\begin{array}{l}L V \text { posterior } \\
\text { wall thickness } \\
(\mathrm{mm})\end{array}$ & $\begin{array}{l}L V \text { septal } \\
\text { wall thickness } \\
(\mathrm{mm})\end{array}$ & $\begin{array}{l}L V \text { inte } \\
\text { dimensic } \\
D_{D}\end{array}$ & $\begin{array}{l}\text { nal } \\
\text { ns (mm) } \\
S_{D}\end{array}$ \\
\hline Control subjects & $\begin{array}{c}9 \cdot 3 \\
(1 \cdot 5)\end{array}$ & $\begin{array}{c}9 \cdot 6 \\
(1 \cdot 2)\end{array}$ & $\begin{array}{l}47 \cdot 7 \\
(1 \cdot 5)\end{array}$ & $\begin{array}{l}323 \\
(2.5)\end{array}$ \\
\hline \multicolumn{5}{|l|}{ Hypertensive: } \\
\hline Group 1 & $\begin{array}{c}9 \cdot 9 \\
(1)\end{array}$ & $\begin{array}{c}9 \cdot 7 \\
(1 \cdot 3)\end{array}$ & $\begin{array}{l}46 \cdot 6 \\
(3 \cdot 1)\end{array}$ & $\begin{array}{l}31 \cdot 2 \\
(4 \cdot 6)\end{array}$ \\
\hline Group 2 & $\begin{array}{l}13.7 \star \\
(1.5)\end{array}$ & $\begin{array}{c}13 \cdot 7^{\star} \\
(1 \cdot 1)\end{array}$ & $\begin{array}{l}44 \cdot 1^{\star} \\
(3 \cdot 8)\end{array}$ & $\begin{array}{c}26 \cdot 7 \star \\
(5 \cdot 3)\end{array}$ \\
\hline Group 3 & $\begin{array}{l}13 \cdot 1^{\star} \\
(1 \cdot 6)\end{array}$ & $\begin{array}{l}13.5^{\star} \\
(1.4)\end{array}$ & $\begin{array}{l}55 \cdot 3 * t \\
(6)\end{array}$ & $\begin{array}{l}44 \cdot 6^{\star} \dagger \\
(8 \cdot 3)\end{array}$ \\
\hline
\end{tabular}

*Significant differences from control subjects $(p<0.01)$.

†Significant differences from hypertensive group $2(p<0.01)$.

with normal or reduced ventricular minor axis. In group 3, in which both aortic diastolic pressure and left ventricular dimensions were increased, circumferential wall stress was increased. Left ventricular filling pressure (pulmonary artery wedge mean pressure) was increased in all three hypertensive groups, though the difference from normal was statistically significant only in group $3(p<0.01)$.

Fig. 3 illustrates the relation between stroke index and left ventricular diastolic diameter. Stroke index was increased in group 2 compared with normal and reduced in group 3, even though diastolic dimension was smaller in the former and greater in the latter group.

\section{Discussion}

The accuracy of the echocardiographic method for measuring ventricular dimensions and wall thickness has been validated in previous reports. ${ }^{8} 12$ It seems reasonable to consider that hypertensive groups in this study were characterised by actual differences in left ventricular structure. Several haemodynamic differences distinguish hypertensive from control subjects as well as one hypertensive group from another. Since the performance of the left ventricle results from interaction of preload, afterload, and contractility, the interplay of these factors should be considered whenever ventricular performance is assessed. Though preload is usually assessed by measuring ventricular diastolic pressure, changes in ventricular distensibility may render the diastolic pressure an unreliable guide to changes in diastolic volume or fibre length. In comparing hypertrophied and non-hypertrophied hearts, equality of ventricular diastolic pressure does not mean equality of initial fibre length because of the lesser distensibility of the hypertrophied heart; it has, in fact, been documented that wall thickness is an important determinant of left ventricular diastolic stiffness and

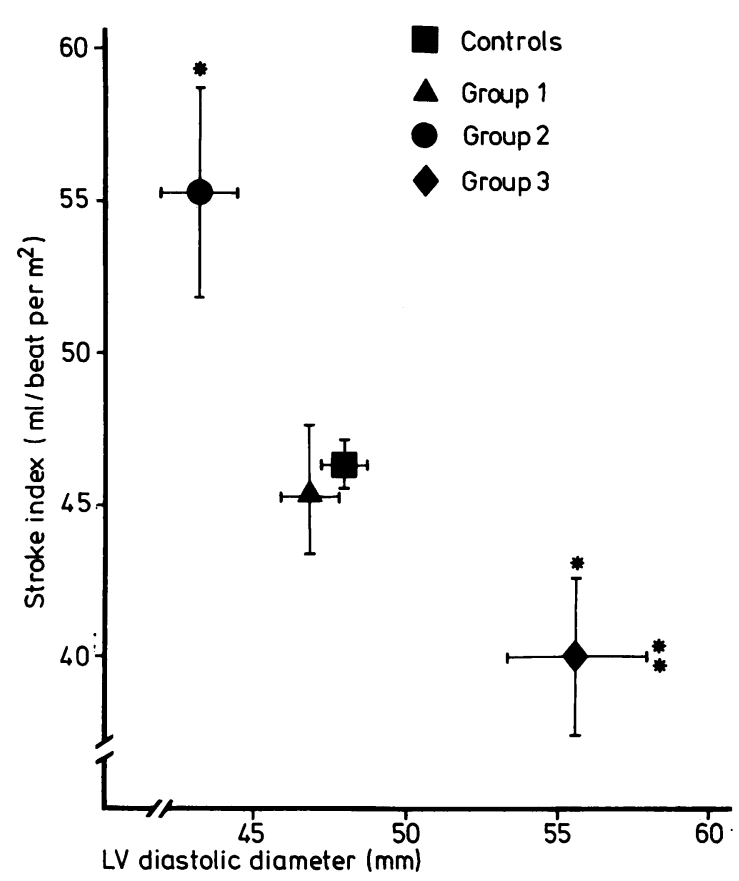

Fig. 3 Relation between left ventricular diastolic diameter and stroke index in control subjects and hypertensive groups (mean $\pm S E M)$. * and $\star \star$ indicate significance of differences from control group, with $p$ values $<0.05$ and $<0.01$, respectively.

pressure. ${ }^{12}$ For these reasons the left ventricular enddiastolic diameter, rather than the diastolic pressure, was used to illustrate the Frank-Starling relation in Fig. 3. Upward displacement from normal in group 2 and downward displacement in group 3 of the stroke index-diastolic diameter relation indicate improved left ventricular function in the former group. Changes in contractility may account for these differences.

Circumferential fibre shortening (VCF) has been regarded by several investigators as a reliable index of the inotropic state of the myocardium. ${ }^{13} 14$ The normal VCF in group 1 , the increase in group 2 , and the decrease in group 3 suggest that contractility is normal in group 1 , increased in group 2 , and reduced in group 3. However, before this interpretation is accepted, the influence of cardiac loading on VCF should be considered. It has been shown that VCF is affected minimally by changes in preload, but responds inversely to changes in afterload ${ }^{15}$ so that changes in afterload may limit the clinical applicability of VCF as an index of contractility. When a low value of VCF is observed in a patient with increased afterload (left ventricular wall stress), 
the question arises whether this value reflects a reduced inotropic state of the myocardium, or results from a shift to a different point on a normal stress-velocity curve.

Circumferential wall stress is increased in groups 1 and 3 and reduced in group 2. However, because circumferential wall stress reflects the load on the left ventricle at the onset of systole, when fibre shortening does not occur, changes in wall stress cannot be related to changes in fibre shortening rate. For a more precise analysis, circumferential fibre shortening rate and wall stress should be measured continuously throughout the ejection phase. This would require high fidelity intraventricular pressure recordings made at the same time as continuous measurements of ventricular internal diameter and wall thickness; however, these measurements are not easily obtained particularly when a computer is not available. Our study does not provide this information and therefore leaves unanswered the question whether the increase in fibre shortening rate in group 2 and its reduction in group 3 are the result of changes in contractility, changes in wall stress, or both. It is likely that an increased velocity of fibre shortening, whatever its cause, is the mechanism by which rate of ejection and stroke index are increased in group 2 despite the higher pressure load and impedance to ejection (peripheral vascular resistance).

The functional capacity of hypertrophied myocardium has been the subject of considerable controversy. ${ }^{16}$ Studies of hypertrophy produced experimentally by ventricular pressure overload, resulting from creation of aortic or pulmonary stenosis, have shown that myocardial contractility is decreased before the development of failure. ${ }^{17} 18$ Other investigators found normal or improved ventricular function in animals with stable hypertrophy from either volume or pressure overload. ${ }^{19-22}$ Skelton and Sonnenblick ${ }^{23}$ have emphasised that changes in myocardial contractility in patients with cardiac hypertrophy are variable and depend upon the causative factor. Earlier reports ${ }^{1-3}$ on hypertensive heart disease suggest that left ventricular function is impaired in the presence of hypertrophy, and the same conclusion was reached in a more recent assessment by Dunn and co-workers. ${ }^{24}$ Our present findings, in agreement with those reported by Karliner and collaborators, ${ }^{25}$ lead to different conclusions, and to a renewal of the controversy about the functional capacity of the hypertrophied myocardium arising from the results of animal experiments. The discrepancy probably results from the substantial difference between present criteria and earlier radiological and electrocardiographic criteria of left ventricular hypertrophy. ${ }^{1-3} 24$

\section{References}

'Sannerstedt R, Bjure J, Varnauskas E. Correlation between electrocardiographic changes and systemic hemodynamics in human arterial hypertension. $A m \mathcal{F}$ Cardiol 1970; 26: 117-22.

${ }^{2}$ Frohlich ED, Tarazi RC, Dustan HP. Clinicalphysiological correlations in the development of hypertensive heart disease. Circulation 1971; 44: 446-55.

${ }^{3}$ Guazzi M, Polese A, Magrini F, Fiorentini C. Correlation of electrocardiographic changes and hemodynamic functions in the treatment of primary arterial hypertension. Am F Med Sci 1974; 267: 299-309.

"McPhie J. Left ventricular hypertrophy: electrocardiographic diagnosis. Aust Ann Med 1958; 7: 31722.

${ }^{5}$ Kilty SE, Lepeschkin E. Effect of body build on the QRS voltage of the electrocardiogram in normal men: its significance in the diagnosis of left ventricular hypertrophy. Circulation 1965; 31: 77-84.

'Drayer JIM, Savage DD, Henry WL, Mathews EC, Laragh JH, Epstein SE. Incidence of echocardiographic left ventricular hypertrophy and left atrial enlargement in essential hypertension (abstract). Circulation 1976; 53 and 54: Suppl II, 233.

'Brodie BR, McLaurin LP, Grossman W. Combined hemodynamic-ultrasonic method for studying left ventricular wall stress. Comparison with angiography. Am $\mathcal{f}$ Cardiol 1976; 37: 864-70.

${ }^{8}$ Feigenbaum H, Popp RL, Wolfe SB, et al. Ultrasound measurements of the left ventricle: correlative study with angiocardiography. Arch Intern Med 1972; 129: 461-7.

'Sandler H, Dodge HT. Left ventricular tension and stress in man. Circ Res 1963; 13: 91-104.

${ }^{10}$ Ratshin RA, Rackley CE, Russell RO Jr. Determination of left ventricular preload and afterload by quantitative echocardiography in man. Circ Res 1974; 34: 711-8.

${ }^{11}$ Fortuin NJ, Hood WP Jr, Craige E. Evaluation of left ventricular function by echocardiography. Circulation 1972; 46: 26-35.

${ }^{12}$ Grossman W, McLaurin LP, Moos SP, Stefadouros M, Young DT. Wall thickness and diastolic properties of the left ventricle. Circulation 1974; 49: 129-35.

${ }^{13}$ Gault JH, Ross J Jr, Braunwald E. Contractile state of the left ventricle in man. Instantaneous tensionvelocity-length relations in patients with and without disease of the left ventricular myocardium. Cir Res 1968; 22: 451-63.

${ }^{14}$ Karliner JS, Gault JH, Eckberg D, Mullins CB, Ross $\mathrm{J} \mathrm{Jr}$. Mean velocity of fiber shortening. A simplified measure of left ventricular myocardial contractility. Circulation 1971; 44: 323-33.

${ }^{15}$ Quinones MA, Gaash WH, Cole JS, Alexander JK. Echocardiographic determination of left ventricular stress-velocity relations in man. With reference to the effects of loading and contractility. Circulation 1975; 51: 689-97.

${ }^{16}$ Meerson FZ. Contractile function of the heart in 
hyperfunction, hypertrophy and heart failure. Circulation 1969; 24 and 25: Suppl II, 9-54.

${ }^{17}$ Spann JF Jr. Heart failure and ventricular hypertrophy. Altered cardiac contractility and compensatory mechanisms. Am f Cardiol 1969; 23: 504-10.

${ }^{18}$ Spann JF Jr, Covell JW, Eckberg DL, Sonnenblick EH, Ross J Jr, Braunwald E. Contractile performance of the hypertrophied and chronically failing cat ventricle. Am F Physiol 1972; 223: 1150-7.

${ }^{19}$ Malik AB, Abe T, O'Kane HO, Geha AS. Cardiac performance in ventricular hypertrophy induced by pressure and volume overloading. I Appl Physiol 1974; 37: 867-74.

${ }^{20}$ Williams JF Jr, Potter RD. Normal contractile state of hypertrophied myocardium following pulmonary artery constriction in the cat. $\mathcal{f}$ Clin Invest 1974; 54: 1266-72.

${ }^{21}$ Pool PE, Piggott WJ, Seagren SC, Skelton CL. Augmented right ventricular function in systemic hypertension-induced hypertrophy. Cardiovasc Res
$1976 ; 10: 124-8$.

${ }^{22}$ Sasayama S, Ross J Jr, Franklin D, Bloor CM, Bishop S, Dilley RB. Adaptations of the left ventricle to chronic pressure overload. Cir Res 1976; 38: 172-8.

${ }^{23}$ Skelton CL, Sonnenblick EH. Heterogeneity of contractile function in cardiac hypertrophy. Circ Res 1974; 34 and 35: Suppl 2, 83-96.

${ }^{24}$ Dunn FG, Chandraratna P, de Carvalho JGR, Basta LL, Frohlich ED. Pathophysiologic assessment of hypertensive heart disease with echocardiography. $\mathrm{Am}$ f Cardiol 1977; 39: 789-95.

${ }^{25}$ Karliner JS, Williams D, Gorwit W, Crawford MH, O'Rourke RA. Left ventricular performance in patients with left ventricular hypertrophy caused by systemic arterial hypertension. Br Heart f 1977; 39: 1239-45.

Requests for reprints to Dr Maurizio D Guazzi, Istituto Ricerche Cardiovascolari, Via Francesco Sforza 35, 20122 Milano, Italy. 